\title{
Timing of deformation in the Four Peaks area, central Arizona, and relevance for the Mazatzal orogeny
}

Calvin A. Mako, Michael L. Williams, Karl E. Karlstrom, Michael F. Doe, David Powicki, Mark E. Holland, George Gehrels, Mark Pecha

\section{DR3- Zircon Age Data Plots}

Below are shown the zircon age distributions and histograms for each sample in this study. Plots were made in the Isoplot 4.1 macro for Microsoft Excel (Ludwig, 2008).

Data for the K13- series samples and sample C13-067b can be retrieved on the Arizona Laserchron Center website under “Current Projects” in the Karlstrom, March, 2014 run.

Figure DR3-1: Sample K13-4PKS-4- Buckhorn granodiorite. (collected by Karlstrom, Powicki, Doe, 2014)

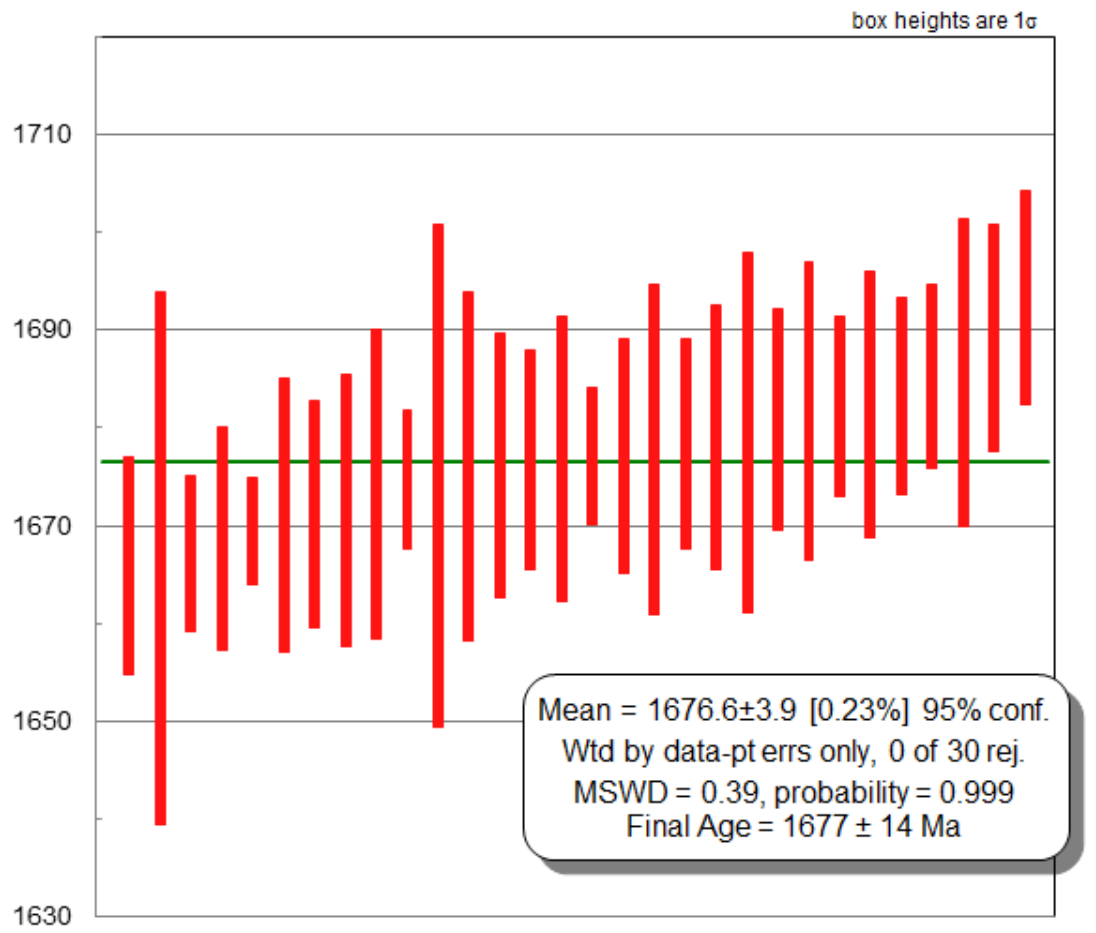


Mako, C.A., Williams, M.L., Karlstrom, K.E., Doe, M.F., Powicki, D., Holland, M.E., Gehrels, G., and Pecha, M., 2015, Polyphase Proterozoic deformation in the Four Peaks area, central Arizona, and relevance for the Mazatzal orogeny: Geosphere, v. 11, doi:10.1130/GES01196.1.

Figure DR3-2:- Sample K13-4PKS-3- Rhyolitic Dike in Buckhorn granodiorite. (collected by Karlstrom, Powicki, Doe, 2014)

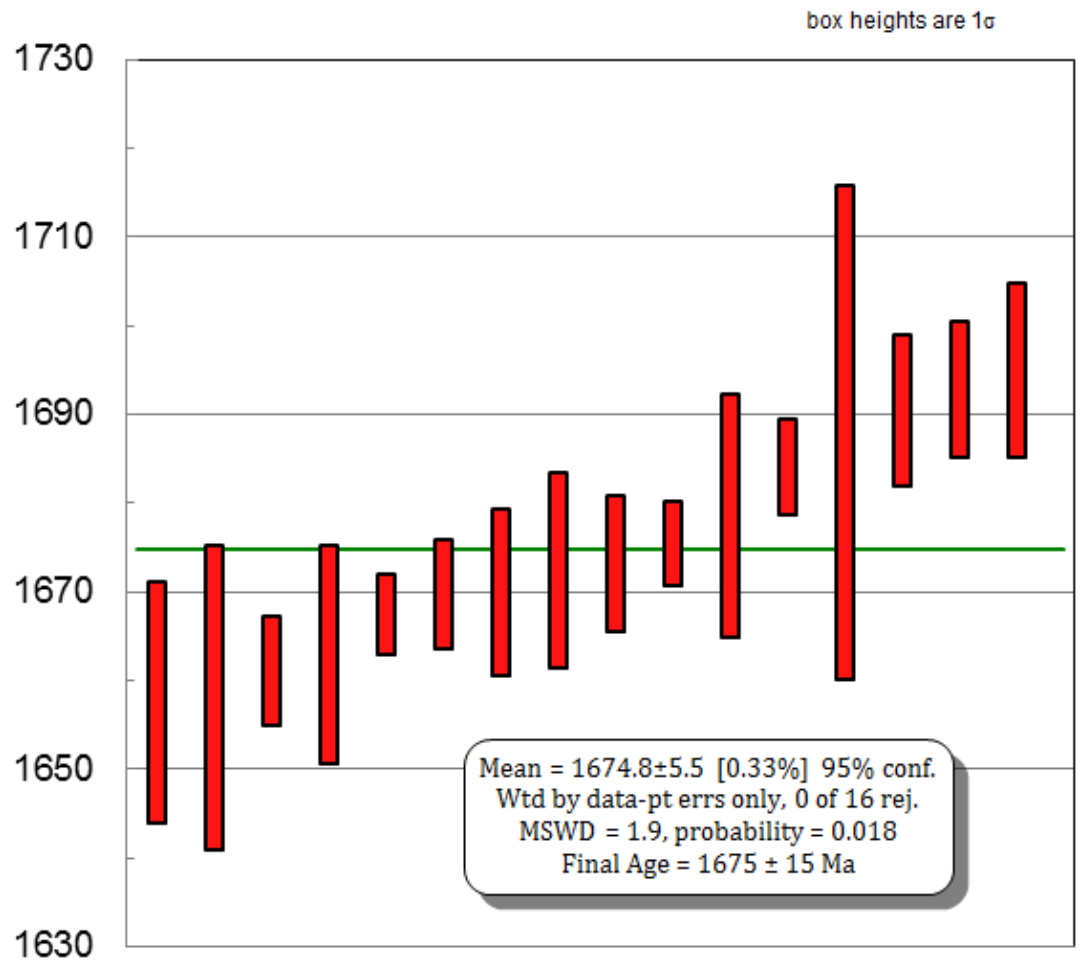

Figure DR3-3: Sample C13-082b- Four Peaks rhyolite. (collected by Mako)

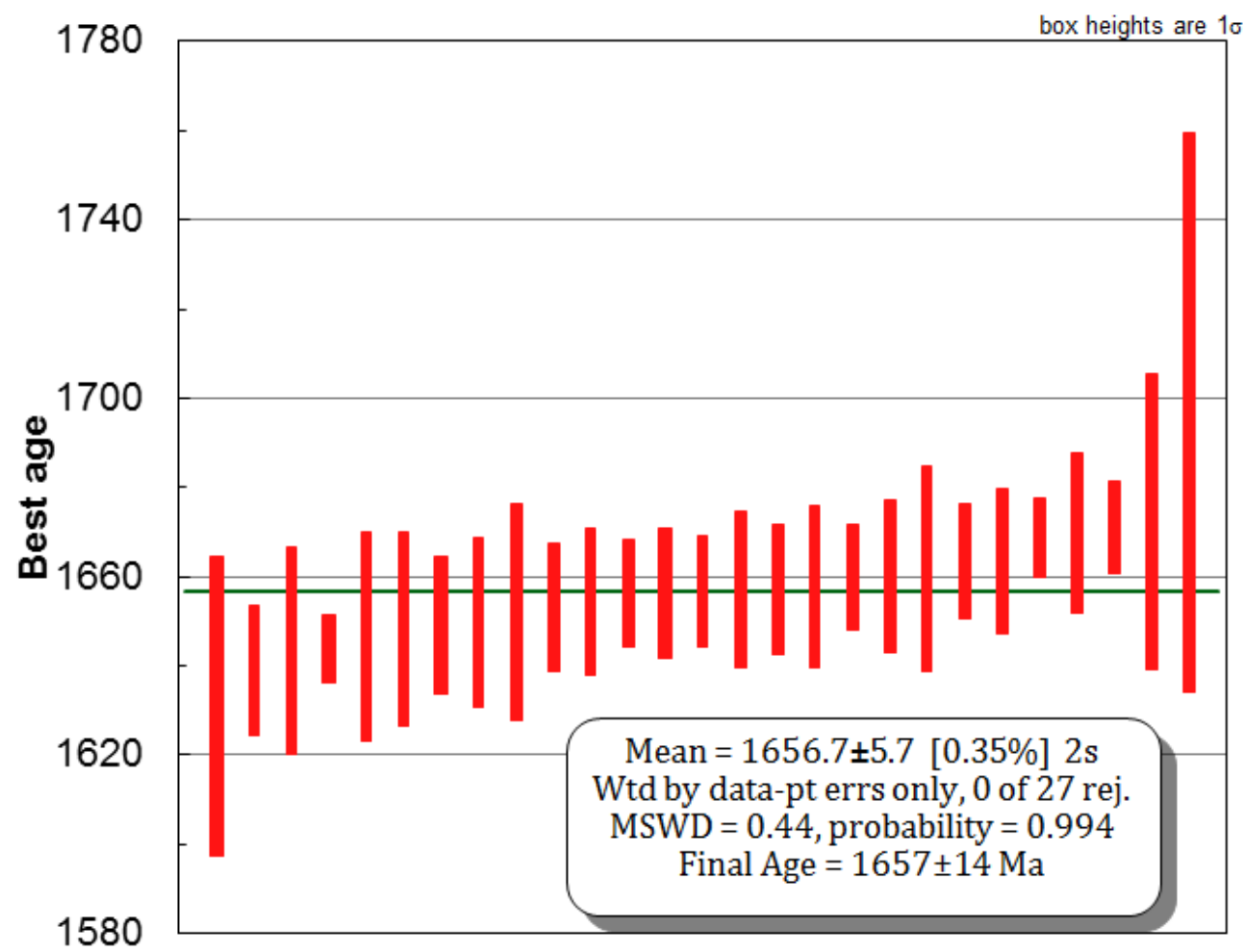


Figure DR3-4: Sample C13-067b- Young Granite. (collected by Mako)

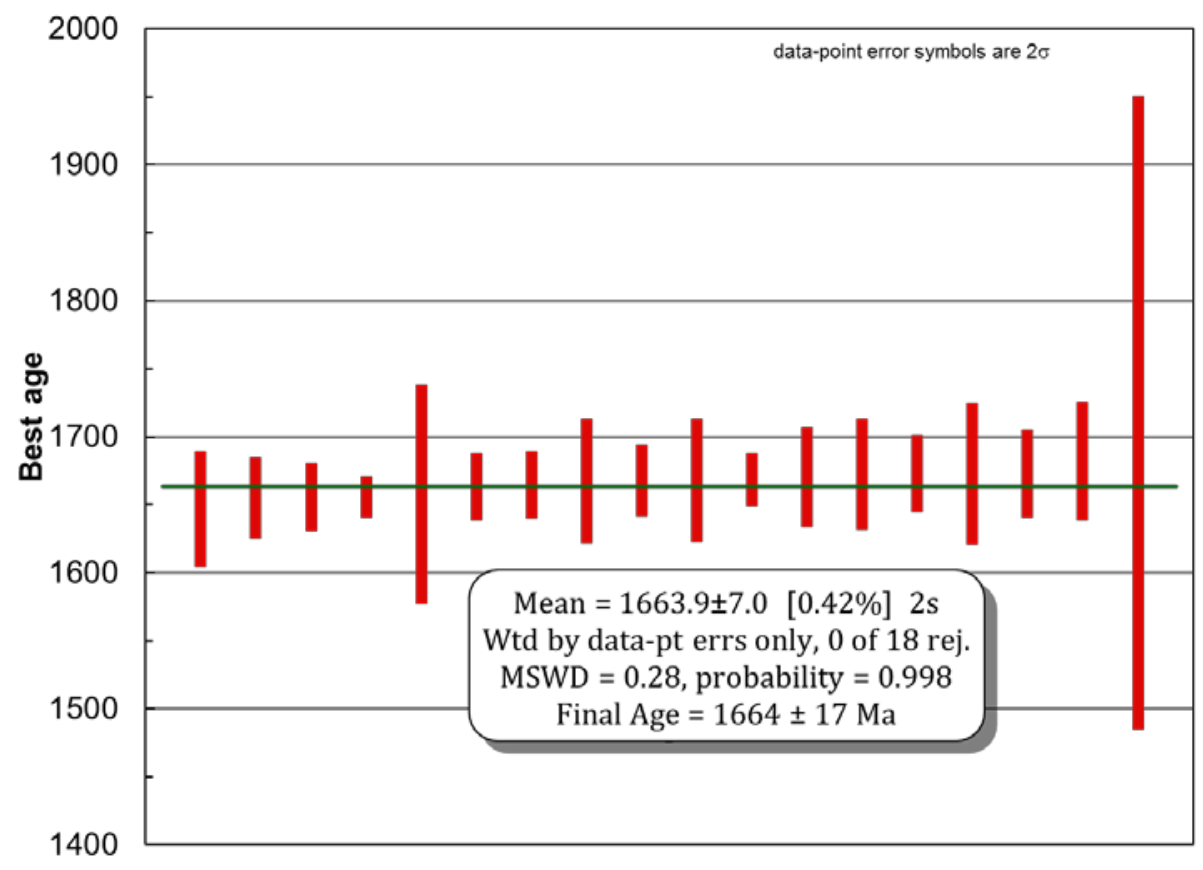

Figure DR3-5: Sample C13-029a- Four Peaks Quartzite. There is one 3500 Ma grain out of view. (collected by Mako)

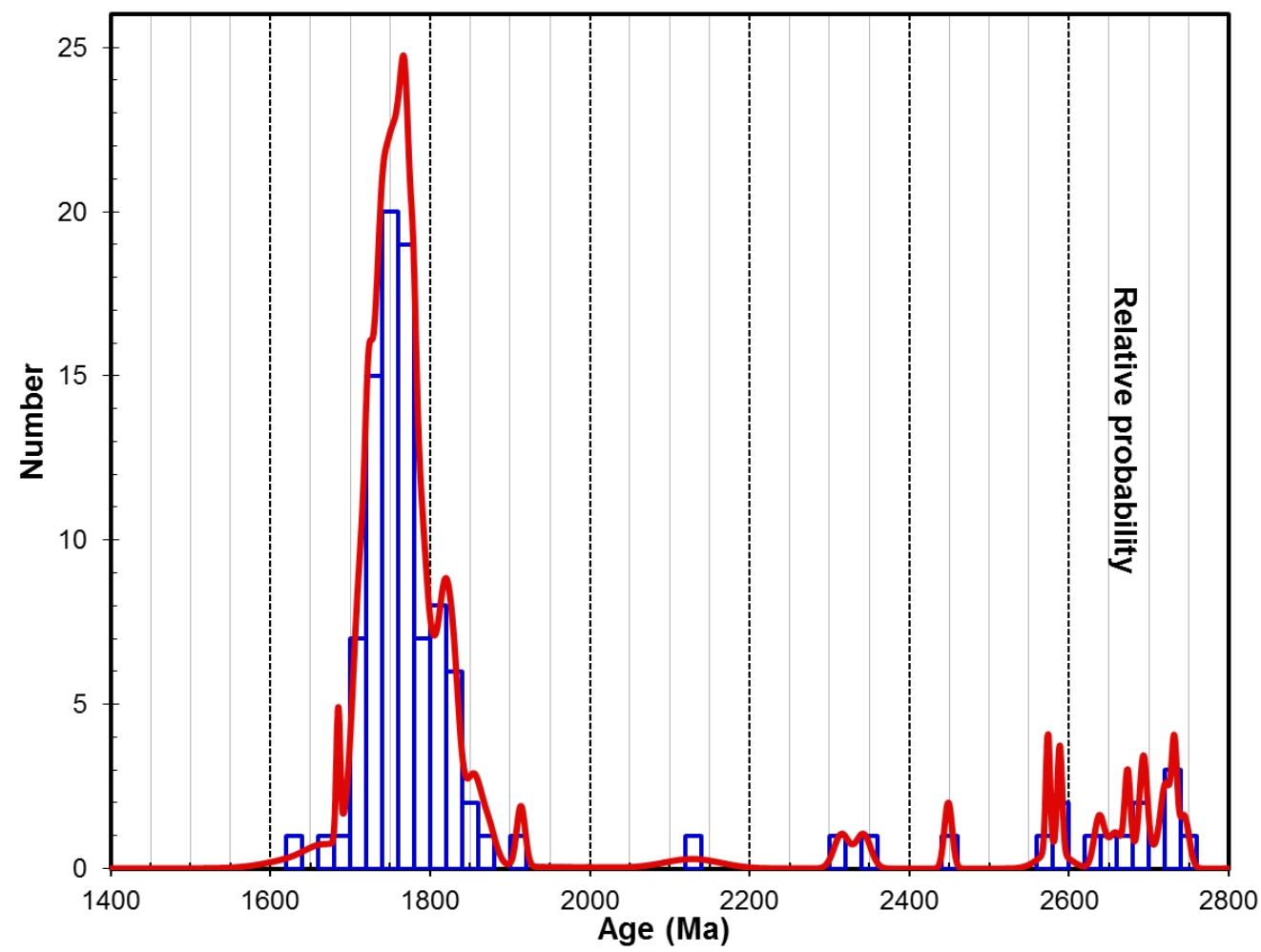


DR3-6: Sample K13-FPKS-14- Biotite, foliated granite of Soldier Camp. (collected by Karlstrom, 2013) The oldest two (inherited) grains were not included in the final age calculation.

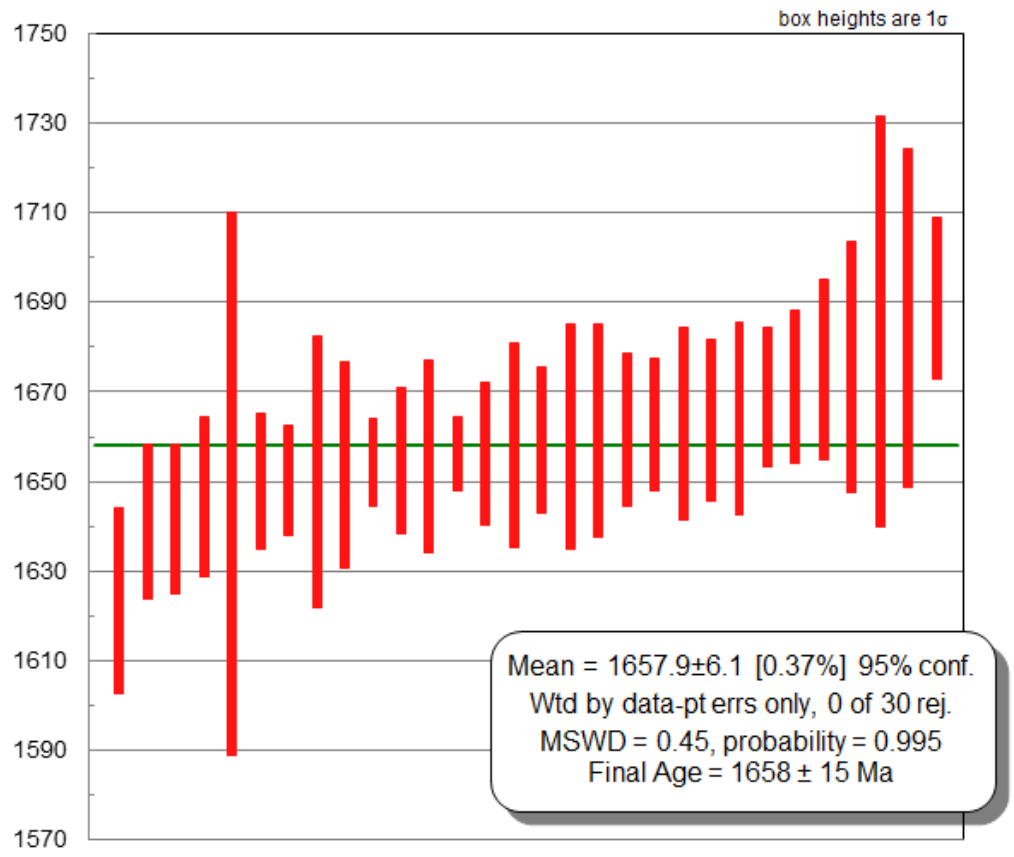

Figure DR3-7: Sample K13-4PKS-5- Megacrystic granite. (collected by Karlstrom, Powicki, Doe, 2014). One old grain (inherited) was not included in the final age calculation.

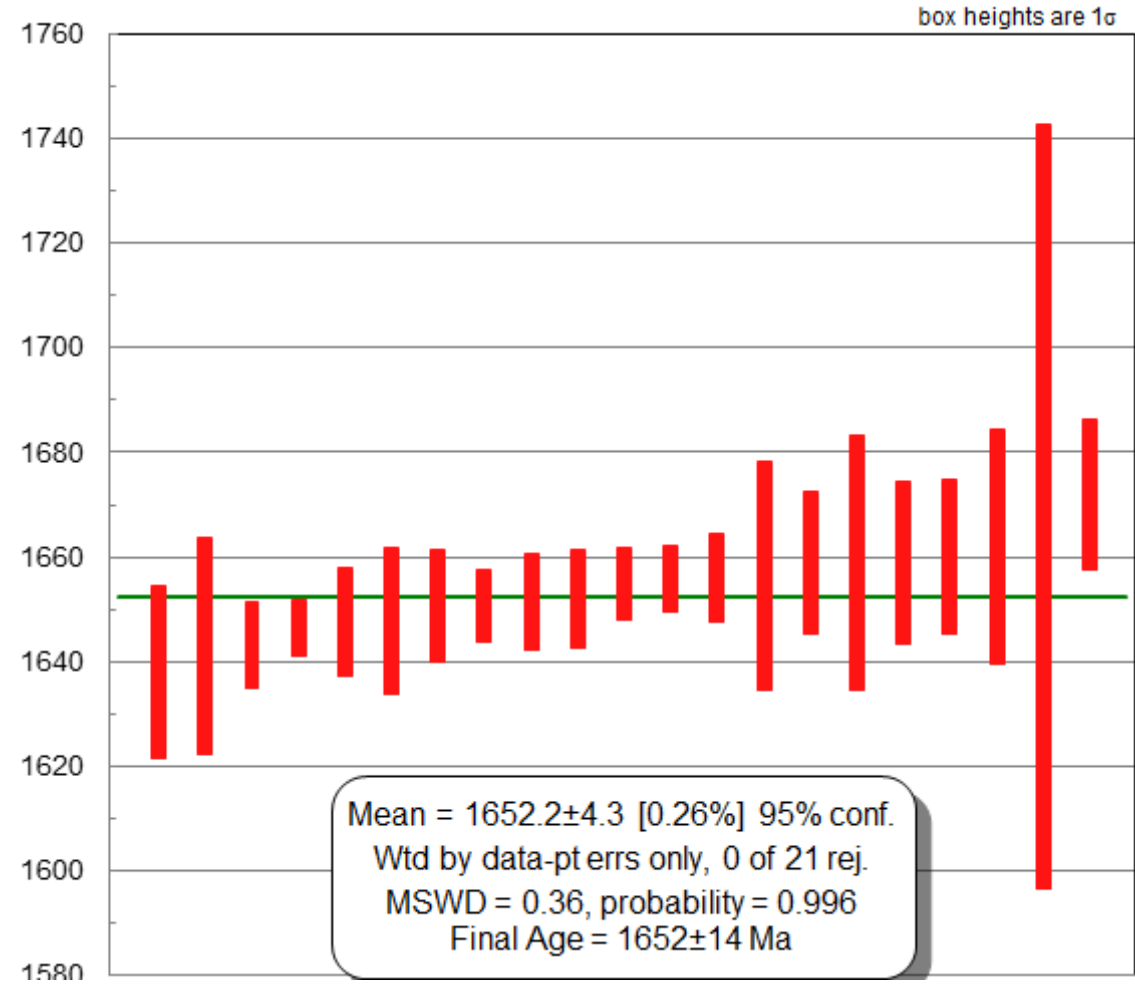


Figure DR3-8: Sample 20130916-1- Upper Sedimentary Unit. (Doe, 2014)

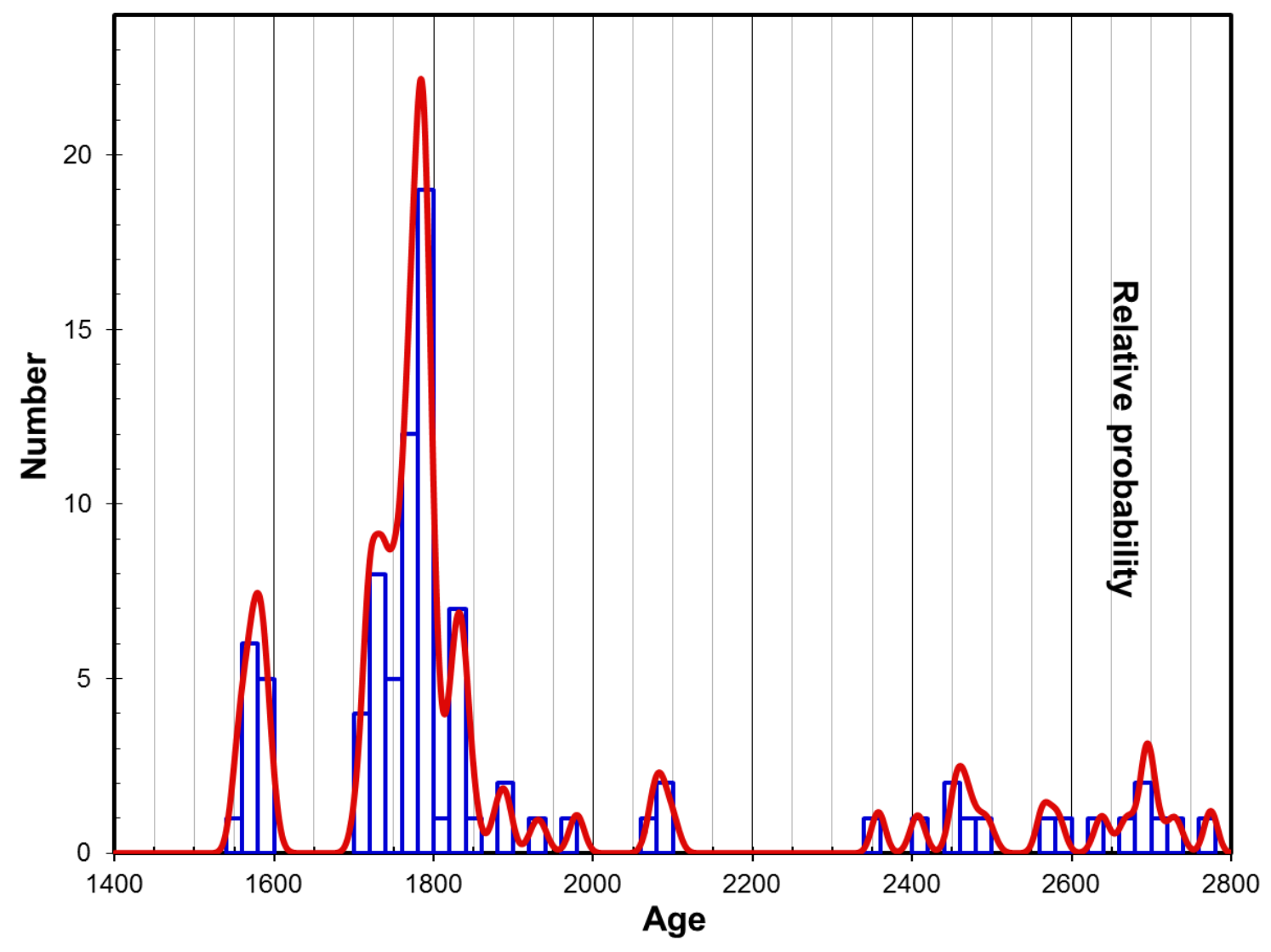

Figure DR3-9: Sample C13-073- El Oso granite. (collected by Mako, 2013) 
Mako, C.A., Williams, M.L., Karlstrom, K.E., Doe, M.F., Powicki, D., Holland, M.E., Gehrels, G., and Pecha, M., 2015, Polyphase Proterozoic deformation in the Four Peaks area, central Arizona, and relevance for the Mazatzal orogeny: Geosphere, v. 11, doi:10.1130/GES01196.1.

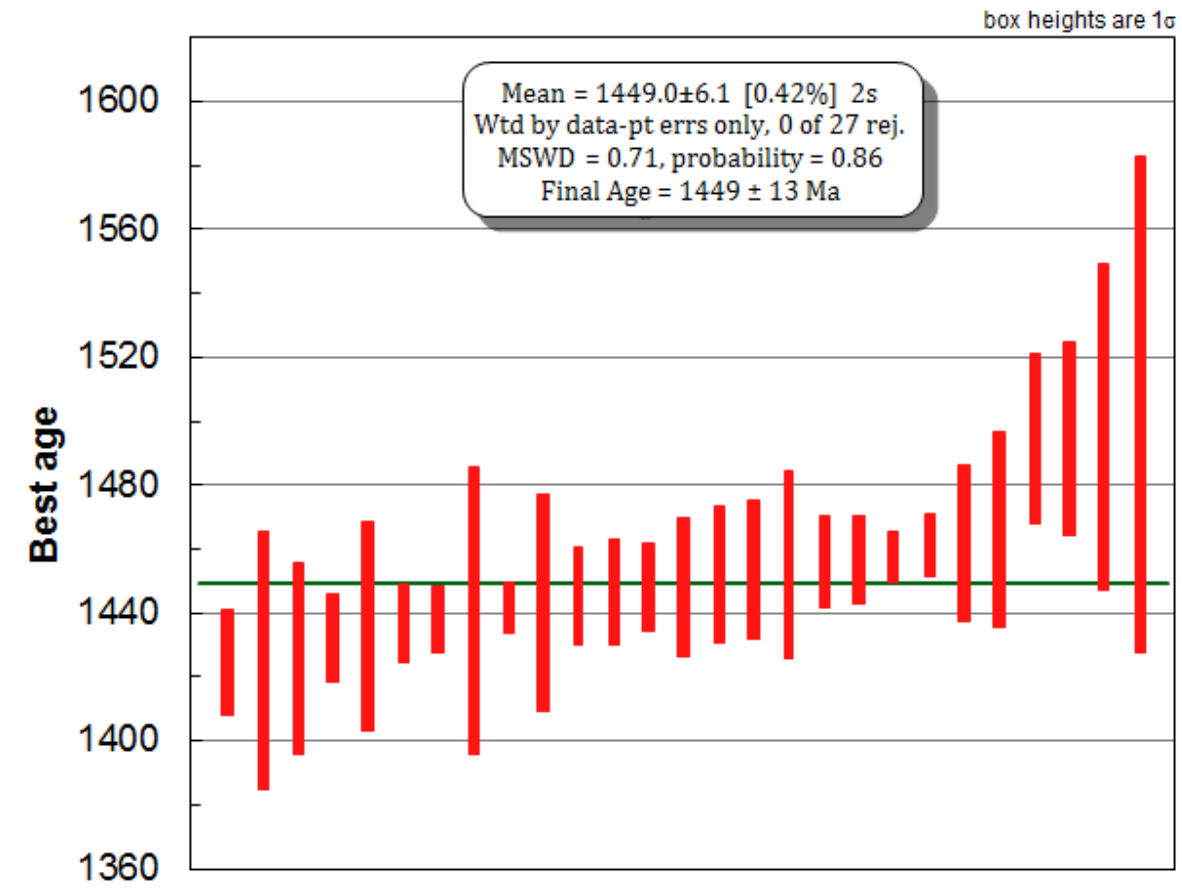

Figure DR3-10: Sample K13-FPKS-15- Musc. granite, Paleo- and Mesoproterozoic grains. (collected by Karlstrom, 2013)

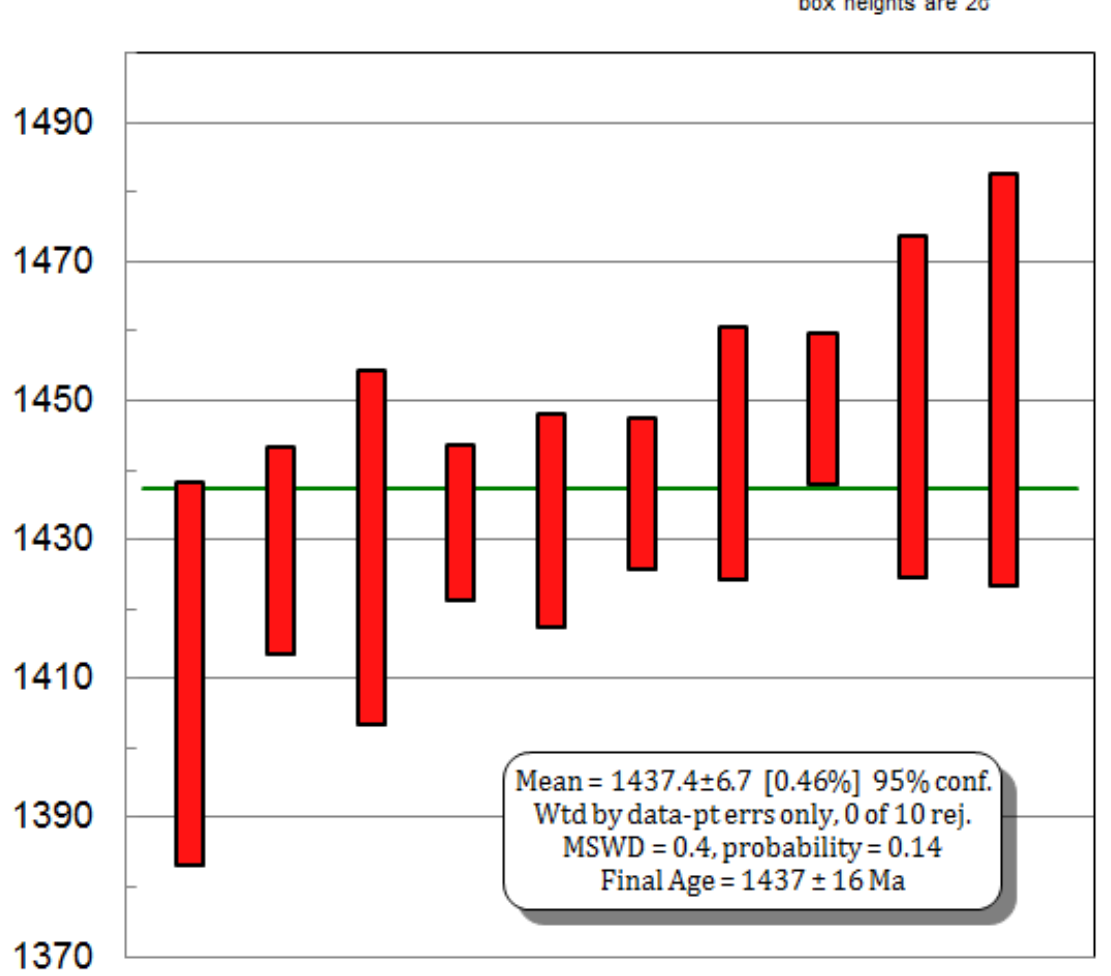


Mako, C.A., Williams, M.L., Karlstrom, K.E., Doe, M.F., Powicki, D., Holland, M.E., Gehrels, G., and Pecha, M., 2015, Polyphase Proterozoic deformation in the Four Peaks area, central Arizona, and relevance for the Mazatzal orogeny: Geosphere, v. 11, doi:10.1130/GES01196.1.

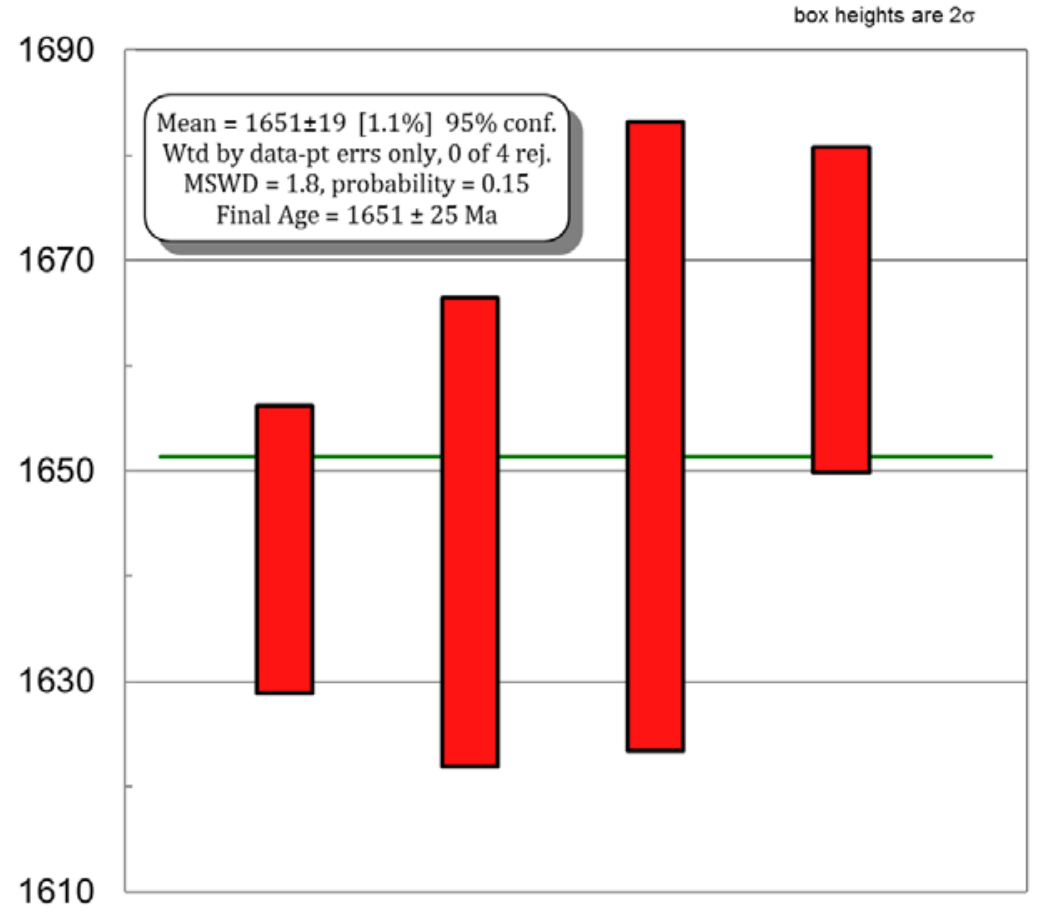

